\title{
Climate Change 101: How Everyday Activities Contribute to the Ever-Growing Issue
}

\author{
https://doi.org/10.3991/ijes.v7i1.10031 \\ Anna Maria Driga ${ }^{(凶)}$, Athanasios S. Drigas \\ National Center for Scientific Research "Demokritos", Agia Paraskevi, Greece \\ anna.maria.driga@gmail.com
}

\begin{abstract}
This article aims at an in-depth analysis of the relation of certain activities and services in daily life to the growth of climate change. Climate change is one of the most characteristic occurrences of the modern world, if not the most. It is a byproduct of the greenhouse effect, which is a natural phenomenon necessary for sustaining life on the planet. However, human activities have heavily contributed to the rise of an unbalanced amount of greenhouse gases in the atmosphere, causing the anthropogenic aspect of climate change. Despite the doubts on the human influence on climate change, there is indisputable scientific proof to verify it. The consequences of climate change appear to be very severe, both for the environment and humans themselves, while they are expected to escalate in the future. It is widely known that the industrial revolution is the landmark of anthropogenic climate change. But despite the industry's influence being common knowledge, what are the everyday actions of each individual or household that are key contributors to the phenomenon?

Transportation is one of the most harmful everyday activities, especially aviation due to emissions from the combustion of fossil fuels used to power the vehicles. Surprisingly, the food industry is also a sector very high in emissions, mostly due to emissions from livestock production. Another cause is deforestation stemming from multiple factors, a very important one being paper production. While trees absorb carbon dioxide, when cut, they emit it back into the atmosphere, resulting in further emissions. Especially damaging is water overuse, due to the disruption of the water cycle. Furthermore, the burning of fossil fuels for general use (e.g. heating) and specifically for electricity is a big contributor in greenhouse emissions. Certain gardening activities can also contribute in the emissions. Lastly, waste is very damaging to the atmosphere. The decomposition of waste is responsible for emitting significant quantities of $\mathrm{CO}_{2}$ and methane. The need to combat climate change is very pressuring. While individual changes in lifestyle are very vital, bigger changes need to be implemented in order to effectively mitigate climate change.
\end{abstract}

Keywords - Climate change; environment; sustainability

\section{Introduction}

The greenhouse effect occurs when select gases (carbon dioxide, methane, nitrous oxide, ozone, water vapor etc.) concentrate in the atmosphere. Such gases are called greenhouse gases and are responsible for trapping the sun's heat into the atmosphere and 
in that way warming the Earth's surface. Eventually, a percentage of the heat is released back into space. [2], [3], [4]

The greenhouse effect is, in actuality, necessary for the heating of our planet. Without it, life on Earth would be impossible. Scientists concluded that the average Earth temperature would be $-18{ }^{\circ} \mathrm{C}$ (current average: $14^{\circ} \mathrm{C}$ ) if it were not for the greenhouse effect. Climate change is the result of the greenhouse effect and was formerly known as a naturally induced phenomenon: evaporation, animal respiration and volcanoes are only few of the natural greenhouse gas sources. However, over the past 50 years, abrupt changes in the world's temperature have been occurring more and more evident, threatening our planet with extreme conditions. After 1950, the natural pattern of atmospheric greenhouse gas concentration was broken and now far exceeding the limit that applied in previous centuries (picture 1). The facts led to the discovery of indisputable evidence linking human activities with the escalation of climate change. Upon research under the IPCC (Fifth Assessment Report), a 95\% probability was determined that human activities heavily contributed in the warming of the planet. Therefore, the term anthropogenic climate change was introduced. When plainly using the term "climate change", usually the anthropogenic aspect of the phenomenon is being referred. Sometimes climate change is also referred to as global warming due to predictions of rising average planet temperature. It is labeled as one of the most crucial matters of our time, often underestimated and/or misunderstood. The starting point for such intense human influence on the climate was the industrial revolution. At that time, carbon dioxide concentration saw an increase of $80 \%$, as the industry is responsible for severe greenhouse emissions. [1], [4], [2]

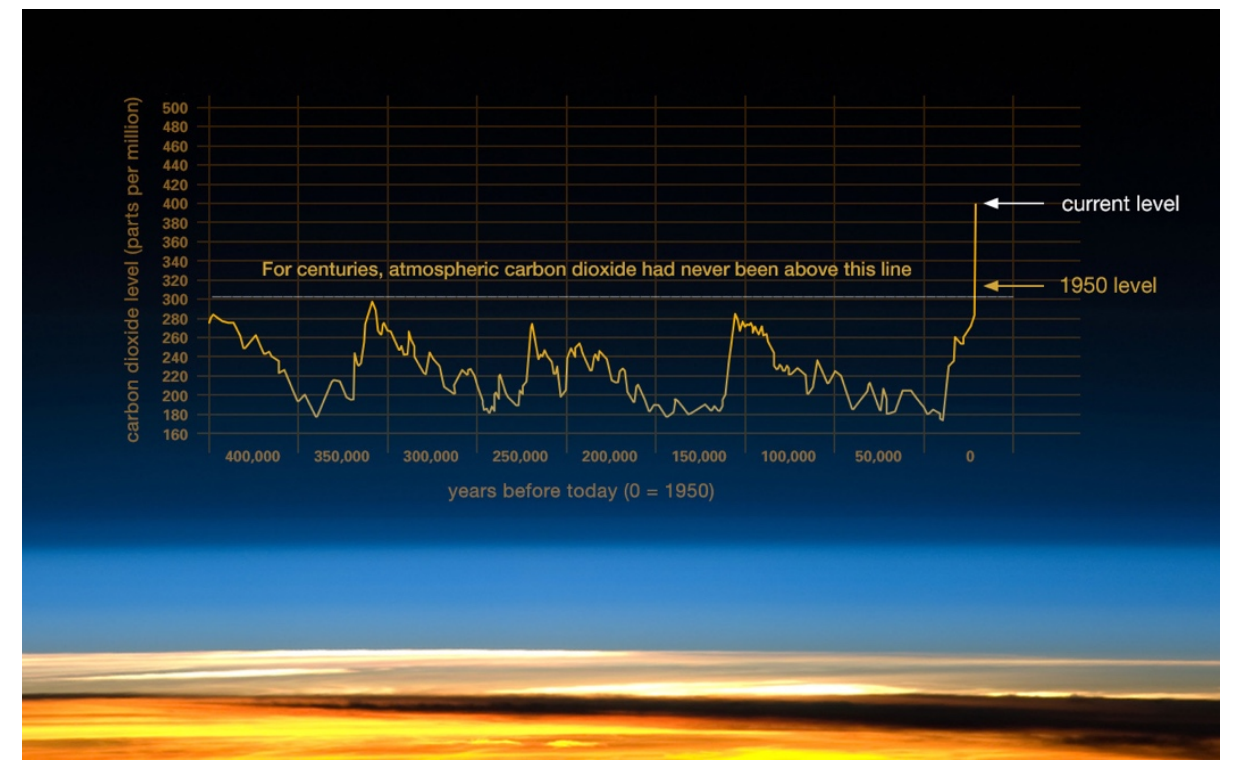

Fig. 1. Picture 1: Vostok ice core data/J.R. Petit et al.; NOAA Mauna Loa CO2 record (source: climate.nasa.gov)

There are multiple things to account as evidence proving the existence of climate change. The most well-known verification is global warming. The average planet 
temperature has increased by $0.9^{\circ} \mathrm{C}$ in the last decades, although for a fuller understanding of the phenomenon separate factor investigation is required. The warming of the planet appears more intense in some places than others. The variations of reactions to climate change in different areas of the world make proving its existence to the public harder. 2010 was one of the warmest years yet, however, the warmest temperatures are yet to come as it is estimated that the northern hemisphere's temperature is set to rise by 5 degrees by 2100 . This excessive heat gathered in our planet is sadly absorbed by oceans as well. An increase of approximately 0.4 degrees Fahrenheit has been detected in the top 700 meters of oceans. This is only the tip of the iceberg regarding the consequences of increasing planet temperature. There has been an astonishing decline in the amount of ice on Earth due to higher temperatures. This can easily be observed by glacier patterns over the decades. One of the most devastating examples is Mount Kilimanjaro (located in Africa) glaciers who have lost their coverage by $85 \%$ from 1912 to mid 2000 's. Research in Tibet showed that from 612 glaciers being studied, $95 \%$ were retreating by 2005 . The snow in the Northern hemisphere is not unaffected as satellite monitoring revealed it's constantly decreasing as well as melting earlier. This also reflects the snow coverage worldwide. The situation with ice coverage is no different. Research under NASA concluded that the ice mass in Greenland diminished by 281 billion tons from 1993 to 2016. Moreover, the ice loss in Antarctica was 119 billion tons in that period. In the last decade, the ice loss in Antarctica has grown three times bigger. The Arctic Sea ice is also diminishing in both volume and quantity with extreme speed. Ice melting, in consequence, leads to an accountable rise in sea level. During the last century, the rise was 8 inches, while it has doubled and going steady as of today. Climate change is also threatening the planet with extreme weather phenomena. Finally, due to the absorption of carbon dioxide, the oceans are acidifying. Every year the amount of carbon dioxide absorbed by oceans is increasing by 2 billion tons. [5], [6].

All these devastating phenomena have immediate consequence on human life and animals as well. First and foremost, forests are heavily impacted by climate change. This impact is varied. In some forests, the tree lines are steadily degrading while in others like the Amazon, even mediocre climate change makes an impact on them. This results in carbon dioxide emissions and air pollution as well as animal endangerment. Climate change is also disrupting Earth's water supply through pollution and through extreme weather conditions, which cause flooding, and drought. Many animal species are also facing extinction while others are threatened by it. The increase in carbon emissions and water temperatures poses a huge threat to oceans, especially coral reefs. This means that the seafood on which many communities rely upon will be in jeopardy. Furthermore, pollution from emissions and extreme weather are also affecting agriculture and food security in general, due to the sector's high reliance on the climate. Thus, not only are humans ruining the planet, but also their own health and well-being as the damage is backfiring. Climate change will be a huge burden on human health, ranging from physical to mental impacts. The declining quality of the air, pollution, high temperatures that make transmitting diseases easier and result in temperature-related death, are only few of the factors that play a part. [7], [8], [9].

This concerning information raises one bigger question: What are the causes of such a threatening phenomenon? Apart from the industry's obvious impact, below is a detailed examination of the causes of climate change that relate to everyday life and the ways they are related as well. 


\section{Transport}

One of the most fundamental anthropogenic factors of the current global warming is today's vast transportation network. The burning of fossil fuels during the function of any motor vehicle is very damaging to the atmosphere as it increases the concentration of carbon dioxide, a greenhouse gas. In the article "Transport and Climate Change" Lee Chapman concludes that the world's population is growing more and more dependent on the different means of transportation. Technological evolution and reduction on vehicle prices play a huge role on the popularization and massive use of private vehicles such as cars and motorcycles, which cause more harm to the environment than public transportation. Many people, in fact, admit to being fully dependent on their personal vehicles according to surveys conducted in the UK. Furthermore, freight shipment across the world impacts the occurrence of climate change heavily. Attention must be drawn to the dangers that aviation causes to the environment, as it was proven to be the highest ranked in greenhouse emissions. The former is also very high in demand, due to the increasing economy, which allows more flight trips to be realized. In other words, frequent rides with a car or motorcycle for everyday activities as well as a habit of traveling distances with airplanes is a key contributor to the greenhouse effect and hence, climate change. People about their everyday lives tend to forget how much the exaggerated usage of motor vehicles impacts the planet. Overall, transport makes up for an astounding $26 \%$ of earth's carbon dioxide emissions. [10]

However, not only does a car release $\mathrm{CO} 2$ when in use, but also from its fuel supply and manufacturing. As S. Potter discovered, on an average car, $73 \%$ of emissions are from the engine, $15 \%$ from the operation of the fueling system and $9 \%$ from the manufacturing of the car. [11] Therefore, it is advised to opt for public transportation instead of a car, and if its use is necessary, the engine should not be left open more than 10 seconds after stopping, in order to minimize emissions.

\section{Food Industry}

The influence of agriculture and food production on climate change is severe. In 2007, greenhouse emissions from this sector were accounted to be $20 \%$ globally. To this day, the percentage is steadily on the rise, and livestock production is especially to blame. This stems from the huge demand and consumption of meat that is characteristic of the modern world. Livestock production is, in fact, responsible for $80 \%$ of the total sector's emissions as greenhouse gases such as methane and nitrous oxide are released in significant amounts. Moreover, the individual average meat consumption was as much as $100 \mathrm{~g}$ daily in the late 2000's. [12] Balancing meals may therefore not only be beneficial to one's health but also to the environment.

In research conducted in Australia, it was found that red meat production plays a big role in the total greenhouse emissions of the country. However, when comparing Australia's emissions with other countries and global statistics, the latter were visibly bigger. [13] This is a positive fact for the country but at the same time disappointing for other countries. Given that Australia is the sixth largest nation in the world, the rest of the nations would be expected to have fewer emissions. 
Another particular food sector that notably burdens global warming is that of fast food. Meats and oils used for fast food production are on the list of the most environmentally threatening. Distribution and transportation also play a big role for this domain's greenhouse emissions. The American agriculture is now being ruled by fast food industries as small farming operations are either being bought off by big corporate industries or forced to abandon their lands. While the business had humble beginnings, over the past few decades it has conquered the American culture. As a result, Americans, more than is spent on any other service, spend hundreds and billions of dollars on fast food annually. This comes in contrast to statistics from previous decades where $75 \%$ of food funds were used for the preparation of homemade meals. In the 1970's concerns were raised by a farm activist that a very well-known food chain would take over America (at the time about 1.000 shops were operating). Now, this has become a reality, as $90 \%$ of the country's new job positions are held by the company. The trend is spreading worldwide as 36.900 stores are operating globally and it was estimated that 2.000 more open each year. [14]

Alcohol production includes many stages that impact the environment: packaging (predominantly glass), fuel use in agriculture, production and, surprisingly, consumption (38, 67 of the sector's emissions). During all of those processes, substantial amounts of greenhouse gases are emitted, although the amount of emissions for each stage as well as altogether is entirely dependent on each producer. There is not enough information to conclude in global statistics while results varied in the countries studied. In the UK alcohol's overall impact on climate change accounts for about 1, 5\%. In specific, beer makes up for $80,5 \%$ of alcohol consumption by volume and is responsible for $62 \%$ of alcohol-related emissions. Similarly, wine consumption is $16 \%$ while emissions reach $27 \%$. For other spirits the consumption rate is $3,5 \%$ and the emission rate is $6,7 \%$. The statistics of this research may not be completely accurate as limited amounts of drinks were investigated and there are also gaps on the evaluation of all the stages. [15]

After gathering knowledge about the impact that food production has on Earth's climate it becomes quite obvious that food waste makes matters much worse. It is impossible for humans to stop consuming food altogether (Tara Garnett). Nevertheless, it is certainly possible to limit food waste and consumption of selected meals like the ones previously mentioned (red meat, fast food, etc.). Food waste is an equally serious and at the same time neglected cause of climate change. Several greenhouse gases are released in production, distribution, storage (refrigeration) packaging and decomposition of food; all stages related to food waste. To grasp an idea of how much harm throwing away food causes, it should be noted that in just the US the production of the food that goes to waste coincides with the emissions of 43 million cars. [16].

\section{$4 \quad$ Paper Production and Deforestation}

A very important part of everyday life and consequently a product with a huge marketing demand is paper. Like every other industrial sector, paper production contains a number of processes harmful to the environment. Those include burning of fossil fuels during multiple production stages, electricity consumption for automated functions, process waste and water use. But, more importantly, paper production is the main cause for deforestation. [17] 
The latter, combined with forest degradation and fragmentation plays a huge part on climate change. Although a big part of the population seems oblivious to the issue, it is constantly getting closer to populated areas. The phenomenon is proved to disrupt nature as much as it does living organisms. Trees naturally absorb carbon dioxide-a harmful greenhouse gas-from the atmosphere and provide the planet with oxygen. Consequently, deforestation causes increased concentration of $\mathrm{CO} 2$ in the atmosphere and thus leads to the expansion of the greenhouse effect, synonymous with global warming. In particular, it accounts for $20-25 \%$ of total greenhouse emissions, as estimated in 2013. [18]

On that topic, a special category worth mentioning is cigarettes and smoking. Fuel and energy consumption, water usage, land use and acidulation from tobacco farming are all contributors to the greenhouse effect. While mostly developed countries use cigarettes, their production generally takes place in developing countries. Additionally, cigarette manufacturing requires, for the biggest part, paper production. In conclusion, this everyday habit for many people is not only affecting themselves but the environment as well. [19]

\section{Water Overuse}

Water is undeniably the most fundamental substance of life, not only on its own as it is also contained in almost every chemical compound. Every living organism is composed of a large percentage of water and also needs to consume significant amounts to survive. It is needed for the growth of each and every plant. Moreover, it is the foundation for every modern production sector (notably the ones previously mentioned): transportation (mainly fuel production), food industry (agriculture, livestock production, alcohol production etc.), paper industry and many more.

This is what the European Environment Agency emphasizes on: every product, service and daily activity of the modern world is based on water usage. In specific, $44 \%$ of total water consumption in Europe is attributed to energy production, 24\% to agriculture and $11 \%$ to industrial purposes. The statistics for individual places in Europe appear to vary and stray from the previous who apply to Europe as a whole. In Southern Europe, $60 \%$ of water consumption is used in agriculture and in other areas; the percentage goes up to $80 \%$. Additionally, $81 \%$ of the water is provided from surface waters (lakes, rivers) who are also the main water provider for the industry, energy production and agriculture. On the other hand, the main water source for the public is ground water, due to its better quality. Very important is the fact that water for industrial use is mainly recycled, while water for public and agriculture use is not. Nowadays, the world water supply is in great jeopardy. As a result, desalination is coming in as a solution, although far from ideal owing to high-energy demands and excessive salt concentration. [20]

The scientific explanation on how water overuse impacts global warming is essentially the disruption of the water cycle. Water in the stage of evaporation helps cool down the atmosphere, so when water is overused and not recycled back into the water cycle, heat from greenhouse gases has more heating power to the planet. Cutting down water use to a minimum is recommended for each individual, while special attention must be drawn to the problem of leaking faucets. 


\section{$6 \quad$ Fossil Fuels and Electricity Overuse}

Although the burning of fossil fuels was briefly touched upon on the transport section, it is a whole topic alone. The chemical combustion of fossil fuels releases greenhouse gas $\mathrm{CO} 2$ and thus contributes to the global warming phenomenon. Carbon dioxide is the leading greenhouse gas in concentration in the atmosphere. Unsurprisingly, the main source of the gas is, as reported, the burning of fossil fuels. Apart from transportation, there are several other uses of fossil fuels required for products and services of daily life. The main ones being most forms of heating and power production as well as industrial use. Hence, great caution is required in the use of heating systems and electricity. Unnecessary use should be avoided both in households and in businesses. [21]

Electricity is the understructure of the contemporary world-as we know it today. But, what is relatively unknown to the public is the connection of power generation to greenhouse gas emissions. Actually, $57 \%$ of total energy required for electricity production is provided by coal combustion. Furthermore, $86 \%$ of US coal utilization is for electricity. Coal is also much higher in emissions than other fossil fuels (oil, natural gas). In the US, electricity is by far the first sector responsible for the most emissions. On the other hand, there are methods of power generation that produce very little emissions to none at all. Those methods are based on renewable energy sources. The former, however, are not widely used, as coal combustion remains the main power source. [22]

\section{Gardening: Land Use, Fertilizers and Lawns}

Land use and climate change are closely interlinked. Significant amounts of greenhouse gases fluctuate between the earth and the atmosphere, making land responsible for a considerable percentage of greenhouse emissions. Plant life and soil function as greenhouse gas deposits, absorbing $\mathrm{CO}_{2}$ through the process of photosynthesis. When the use of land changes, methane and nitrous oxide are released back into the atmosphere. Also, land clearing can damage soil's ability to store carbon and nitrogen. Land use is not only disturbed from gardening. Agriculture and land clearance for estate building are additional anthropogenic causes. [23], [24]

The lawn is a very popular gardening component of today. However harmless it may seem, it is very damaging to the atmosphere. The mowing, watering and fertilizing it requires consume energy, while frequent lawn trimming releases carbon dioxide into the atmosphere. Consequently, lawns do not only release more gases than they absorb, but make up for a great quantity of emissions. The latter are equal to $2 / 3$ of the agriculture emissions of certain US areas studied. On a positive note, there are several eco-friendly alternatives to replace the traditional lawn. [25]

Fertilizers are an important source of nitrogen and carbon emissions as well. In addition, their manufacturing requires ammonia production, which leads to $\mathrm{CO}_{2}$ emissions. In the UK, the use of fertilizers augmented by $300 \%$ during the mid $20^{\text {th }}$ century. [23] 


\section{Waste Decomposition}

Last but most certainly not least is the impact of waste on the environment. Along with food waste, every other type of waste is remarkably wounding to the atmosphere. The decomposition of waste leads to effective greenhouse gas production. The main gas produced is methane. The latter is formed from the decomposition of organic matters in landfills. Although methane is not a long-lasting greenhouse gas, its impact is incredibly overwhelming. Every ton of methane withholds as much heat in the atmosphere as 84 tons of carbon dioxide (this applies for the next 20 years' impact). It was predicted that by eliminating just $40 \%$ of methane emissions, the progress of climate change is going to be delayed by 15 years. In the US, 426 million metric tons of $\mathrm{CO}_{2}$ are emitted from landfills every year. This equals to a 20 years' impact of emissions. Therefore, the importance of regulating waste and recycling is now bigger than ever. [26]

\section{Conclusion}

In conclusion, a fundamental change in values is required, both by each individual and by society as a whole. From the studies reviewed, it is clear that the future is not looking bright on the prospect of climate change mitigation. Changes in daily life are necessary if any kind of positive change is to be seen in the near future. Those changes include committing to the use of public transportation, eliminating food waste in households, consuming less red meat, minimizing water, power and paper use as well as overuse of heating systems. While those changes seem small and unnecessary, if applied they could have a considerable impact on eliminating the growth of climate change. Of course a positive impact won't be viable unless there are societal and international changes as well.

Some propositions of important steps and at the same time applicable solutions include:

- Switching to renewable power sources in order to avoid the mass burning of fossil fuels for power generation.

- Making education digital and independent from paper books in order to eliminate deforestation.

- Implementing laws towards recycling and the responsible use of water.

- Close monitoring of the agriculture and livestock production sectors, as most decisions regarding environmentally friendly choices are currently up to each individual owner of farming businesses.

- Limit the number of cars that run on internal combustion engines

- Modify fuel powered car engines towards a more efficient burning of fossil fuels.

- Restriction of environmentally harmful activities related to local and international customs such as: cutting down real trees for Christmas, tremendous food waste on the Italian battle of oranges custom. 


\section{Acknowledgement}

This work was accomplished in the framework of the ERASMUS+ (Cooperation for innovation and the exchange of good practices- Capacity Building in the field of Higher Education-Key Action 2) project entitled "CLICHA: Climate Change in Agriculture" (Project Number - 586273-EPP-1-2017-1-EL-EPPKA2-CBHE-JP).

\section{References}

[1] IPCC Fifth Assessment Report (2014). https://www.ipcc.ch/report/ar5/syr/

[2] Climate Change Causes. NASA https://climate.nasa.gov/causes/

[3] Greenhouse Effect. Australian Government, Department of the Environment and Energy. http://www.environment.gov.au/climate-change/climate-science-data/climatescience/greenhouse-effect

[4] Kim Rutledge et al. Greenhouse effect. National Geographic. https://www.nationalgeographic.org/encyclopedia/greenhouse-effect/

[5] Evidence/Facts. NASA https://climate.nasa.gov/evidence/

[6] Lonnie G. Thompson. Climate Change: The Evidence and our Options Behav Anal. 2010 Fall; 33(2): 153-170. https://doi.org/10.1007/BF03392211

[7] The Effects of Climate Change. WWF www.wwf.org.uk/effectsofclimatechange

[8] Climate Impacts on Agriculture and Food Supply. United States Environmental Protection Agency. https://19january2017snapshot.epa.gov/climate-impacts/climate-impacts-agricultureand-food-supply_html

[9] The Impacts of Climate Change on Human Health: A Scientific Assessment. US Global Change Research Program. https://health2016.globalchange.gov/

[10] Lee Chapman. Transport and Climate Change: a review Journal of Transport Geography Volume 15, Issue 5, September 2007, Pages 354-367 https://doi.org/10.101 6/j.jtrangeo.2006.11.008

[11] S. Potter (2003). Transport Energy and Emissions: Urban Public transport. In: Hensher, David and Button, Kenneth eds. Handbook of transport and the environment, 4. Handbooks in Transport. Amsterdam, Netherlands: Elsevier, pp. 247-262. https://doi.org/10. 1108/9781786359513-013

[12] Anthony J McMichael et al. Food, livestock production, energy, climate change, and health. The Lancet (October 2007), Volume 370, Issue 9594, Pages 1253-1263.

[13] Gregory M. Peters et al. Red Meat Production in Australia: Life Cycle Assessment and Comparison with Overseas Studies. Environ. Sci. Technol.2010, 44, 4, 1327-1332 https://doi.org/10.1021/es901131e

[14] Eric Schlosser. Fast food nation: the dark side of the all-American meal. Paperback - Black \& White, July 5, 2005

[15] Tara Garnett. The alcohol we drink and its contribution to the UK's greenhouse gas emissions: a discussion paper. Food Climate Research Network. February 2007

[16] https://www.fcrn.org.uk/sites/default/files/ALCOHOL\%20final\%20version\%20TG\%20feb\%2 02007.pdf

[17] Chad Frischmann. Food Waste is a vastly overlooked driver of climate change. The Washington Post. https://www.washingtonpost.com/news/theworldpost/wp/2018/07/31/foodwaste/?noredirect=on\&utm_term $=$.f064419fa207

[18] Dr Roux. The Pulp and Paper Industry and Climate Change Mitigation. Regional Activity Centre for Sustainable Production and Consumption. http://www.cprac.org/ 
[19] Mrs Archana K. Impact of Deforestation on Climate Change. IOSR Journal Of Environmental Science, Toxicology And Food Technology (IOSR-JESTFT) e-ISSN: 2319-2402, p- ISSN: 2319-2399. Volume 4, Issue 2 (May. - Jun. 2013), PP 24-28 www.Iosrjournals.Org.

[20] Maria Zafeiridou et al. Cigarette Smoking: An Assessment of Tobacco's Global Environmental Footprint Across Its Entire Supply Chain. Environ. Sci. Technol. 2018, 52, 15, 8087-8094. https://doi.org/10.1021/acs.est.8b01533

[21] Robert Collins et al. Water resources across Europe - confronting water scarcity and drought. European Environment Agency Report: No 2/2009. ISSN 1725-9177

[22] Donald J. Wuebbles, Atul K. Jain. Concerns about climate change and the role of fossil fuel use. Fuel Processing Technology Volume 71, Issues 1-3, June 2001, Pages 99-119. https://doi.org/10.1016/S0378-3820(01)00139-4

[23] Electricity and Climate Change. Power Scorecard. $\mathrm{http}: / /$ www.powerscorecard.org/issue detail.cfm?issue id=1

[24] M.D.A. Rounsevell, D.S. Reay. Land Use and Climate Change in the UK. Land Use Policy Volume 26, Supplement 1, December 2009, Pages S160-S169. https://doi.org/10. 1016/j.landusepol.2009.09.007

[25] Land Use Changes \& Climate. The Environmental Literacy Council. https://enviroliteracy.org/air-climate-weather/climate/land-use-changes-climate/

[26] Chuanhui $\mathrm{Gu}$ et al (2015). The effects of household management practices on the global warming potential of urban lawns. Journal of Environmental Management 151C:233-242. https://doi.org/10.1016/j.jenvman.2015.01.008

[27] Kate Bailey (24 Feb 2017). How the Waste Industry Can Lead on Climate Change. Waste360.com https://www.waste360.com/emissions/how-waste-industry-can-lead-climatechange

\section{Authors}

Anna Maria Driga, is with N.C.S.R. "Demokritos", Institute of Informatics and Telecommunications, Net Media Lab, Agia Paraskevi, 153 10, Athens, Greece (e-mail: anna.maria.driga@gmail.com).

Athanasios S. Drigas is with N.C.S.R. "Demokritos", Institute of Informatics and Telecommunications, Net Media Lab, Agia Paraskevi, 153 10, Athens, Greece (e-mail: dr@iit.demokritos.gr).

Article submitted 2018-12-20. Resubmitted 2019-01-27. Final acceptance 2019-01-29. Final version published as submitted by the authors. 